\section{Saúde e ambiente em sua relação com o consumo de agrotóxicos em um pólo agrícola do Estado do Rio de Janeiro, Brasil}

\author{
Health, environment, and pesticide use in a \\ farming area in Rio de Janeiro State, Brazil
}

Frederico Peres 1

Josino Costa Moreira 1

\footnotetext{
${ }_{1}$ Escola Nacional de Saúde Pública Sergio Arouca, Fundação Oswaldo Cruz, Rio de Janeiro, Brasil.

Correspondência F. Peres

Centro de Estudos da Saúde do Trabalhador e Ecologia Humana, Escola Nacional de Saúde Pública Sergio Arouca, Fundação Oswaldo Cruz. Rua Leopoldo Bulhões 1480, Rio de Janeiro, $R J$ 21041-210, Brasil. fperes@fiocruz.br
}

\begin{abstract}
Pesticide use in agriculture is a nationwide phenomenon in Brazil, and the problem is proportional to this vast country. The widespread and growing use of pesticides for crops and cattleraising, among other applications, has caused a number of environmental changes and problems, both by contaminating the communities of living beings that comprise the environment and by accumulating in the biotic and abiotic segments of ecosystems (biota, water, air, soil, sediments etc.). Pesticides also cause a number of diseases and health problems in human populations. The current article discusses several pesticide-related implications for human health and the environment in the mountainous region of the State of Rio de Janeiro, an important farming center. The article presents the results of research in the area, identifying possible determinants of the current situation and some of the main challenges for dealing with the problem.
\end{abstract}

Pesticide Utilization; Rural Workers; Environmental Pollution

\section{Introdução}

O Brasil figura entre os principais consumidores mundiais de agrotóxicos. Os dados a respeito de sua colocação no ranking desses consumidores são conflitantes e, portanto, imprecisos. De acordo com a Organização das Nações Unidas para a Agricultura e a Alimentação (FAO), o Brasil é o quarto maior consumidor mundial de agrotóxicos 1. Já o Sindicato Nacional da Indústria de Produtos para Defesa Agrícola (SINDAG), cujos dados de consumo de agrotóxicos são utilizados pelas agências do governo brasileiro, coloca o Brasil no terceiro lugar do ranking dos principais países consumidores de agrotóxicos 2 .

Entre 1964 e 1991, o consumo de agrotóxicos no país aumentou $276,2 \%$, frente a um aumento de $76 \%$ na área plantada 3 . Já no período entre 1991 e 2000, observou-se um aumento de quase $400 \%$ no consumo desses agentes químicos, frente a um aumento de $7,5 \%$ na área plantada 1 . Entre 1991 e 1997, os gastos mundiais com agrotóxicos aumentaram de 20 para 34 bilhões de Dólares/ano ${ }^{4}$. A América Latina foi a região do planeta onde se observou um maior aumento no consumo desses produtos (aproximadamente $120 \%$ ), muito em parte pela influência do Brasil que, no período, aumentou seu gasto na aquisição desses insumos de 1 para 2,2 bilhões de Dólares/ano. Hoje, estima-se que o país gaste em torno de 6,5 bilhões de Dólares/ano com esses agentes químicos 2 . 
O agronegócio é, hoje, o maior setor exportador brasileiro, representando $42 \%$ das exportações de nosso país, de acordo com dados do Ministério da Agricultura, Pecuária e Abastecimento ${ }^{5}$. As vendas ao exterior realizadas pelo setor totalizaram em 2004, 39 bilhões de Dólares, valor $27 \%$ superior ao obtido no ano anterior. Sua contribuição é determinante para o superávit da balança comercial do país, sobretudo em função do cultivo de soja na Região Centro-Oeste. Alguns estudos 6,7,8,9 vêm apontando a relação entre a expansão da soja e o aumento do uso de agrotóxicos, particularmente com a adoção da soja transgênica.

Além da soja, que é hoje a principal commodity agrícola de nosso país, destaca-se, também, o aumento da produtividade da olericultura nacional que, apesar de destinada prioritariamente ao abastecimento do mercado interno, vem registrando, ano após ano, recordes de safras e um crescimento, no período entre 1980 e 2000, da ordem de $95 \%$ 10. A relação entre a produção olerícola e o consumo de agrotóxicos merece particular destaque em função da complexidade de fatores a esta relação condicionados. Um dos principais fatores é o predomínio da agricultura familiar nesse setor da agroindústria, o que freqüentemente determina o envolvimento de toda a família no processo produtivo, a policultura ininterrupta ao longo do ano, a pouca mecanização das diversas etapas do processo produtivo e a multiexposição a uma série de contaminantes ambientais - agrotóxicos principalmente - no desenvolvimento das atividades de trabalho 7,9 .

Uma série de estudos realizados no Brasil 11,12,13,14 e em outros países 15,16,17,18,19, tem mostrado o grande desafio que é o enfrentamento dos problemas de saúde e de ordem ambiental relacionados com o manejo de agrotóxicos na agricultura familiar: exposição de todo o núcleo familiar aos efeitos nocivos destes agentes; contaminação do ambiente intradomiciliar; processos de descarte de embalagens vazias inadequados; pouca atenção à destinação dos resíduos do processo produtivo, entre outros.

No Estado do Rio de Janeiro, esse tipo de produção agrícola se concentra, predominantemente, na região serrana, principal pólo olerícola do estado, responsável pelo abastecimento da região metropolitana. Nessa região, há o predomínio da agricultura familiar intensiva, onde os problemas mencionados anteriormente são amplamente observados 20 .

O consumo de agrotóxicos na região serrana do Estado do Rio de Janeiro é elevado, podendo chegar a 56,5kg/trabalhador/ano 20 , valor este cinco vezes superior à média da Região Sudeste e 18 vezes maior que a média do estado 11. A Empresa Estadual de Pesquisa Agropecuária do Rio de Janeiro (PESAGRO-RIO), através da Estação Experimental de Nova Friburgo, em parceria com a Associação Brasileira de Agricultura Biológica (ABIO), realizou levantamento que demonstrou que dos 32 agrotóxicos mais usados, 17 sofrem sérias restrições em outros países, sendo que oito deles já foram, inclusive, proibidos 21 .

Na região se destaca, entre outras, a produção de tomate, particularmente nos Municípios de Nova Friburgo, Paty do Alferes, Bom Jardim, Santo Antônio de Pádua, Sumidouro e Teresópolis. Historicamente, o Brasil ocupa uma posição destacada entre os dez maiores países produtores de tomate no mundo e a Região Sudeste é responsável pela maior produção nacional de tomate para mesa e indústria 22. É uma das hortaliças mais importantes no Brasil, considerando-se seus aspectos sócio-econômicos 23 e, também, um dos cultivos onde mais se observa aporte de agrotóxicos. Diversos estudos vêm apontando os impactos à saúde e ao ambiente decorrentes do uso de agrotóxicos nas lavouras de tomate $24,25,26,27,28$. Esses aspectos serão posteriormente discutidos neste artigo, com base em alguns estudos de caso desenvolvidos na região serrana do Estado do Rio de Janeiro.

A intensa produtividade, a agricultura familiar, a policultura e o fato de, na região, preponderarem pequenas propriedades rurais (sítios de 1 a 12ha), caracterizam um perfil de produção fruto da origem européia dos núcleos familiares ali residentes (em especial suíços e germânicos). O regime anual de uso de agrotóxicos na região apresenta uma variabilidade que acompanha diretamente a sazonalidade da produção: observa-se um maior aporte destas substâncias nas lavouras de verão, em especial a do tomate, com as lavouras de inverno - destaque para as culturas da couve-flor e abobrinha - consumindo aproximadamente $1 / 3$ do montante utilizado entre os meses de setembro e abril (predomínio das culturas de verão).

Alguns estudos apontam a baixa adesão aos equipamentos de proteção individual entre os trabalhadores da região 29,30,31,32, outro fato que influencia diretamente na determinação da situação de vulnerabilidade destes trabalhadores frente aos efeitos nocivos do uso de agrotóxicos nos processos produtivos rurais 33 . O presente trabalho tem por objetivo discutir o uso de agrotóxicos na olericultura da região serrana do Estado do Rio de Janeiro, focalizando os principais impactos dessa atividade para a saúde humana e o ambiente, a partir dos resultados de estudos desenvolvidos por nosso grupo de pesquisa há nove anos na região, entre outros estudos. 


\section{Agrotóxicos e a saúde humana}

Os agrotóxicos são agentes químicos que determinam uma série de efeitos nocivos à saúde humana. De acordo com a classe química a que esses produtos pertencem e o tipo de exposição, podem causar desde dermatites até alguns tipos de cânceres (Tabela 1). De acordo com o Sistema Nacional de Informações Tóxico-farmacológicas (SINITOX), dentre os 530 óbitos registrados pelos Centros de Controle de Intoxicações em 2003, os principais agentes tóxicos envolvidos foram os agrotóxicos de uso agrícola, correspondendo a mais de $30 \%$ das causas do total de óbitos 34 . Para o sexo masculino, esses agentes químicos representaram aproximadamente $40 \%$ do total de óbitos registrados.
Os inseticidas da classe dos organofosforados, bem como os carbamatos, atuam no organismo humano inibindo uma enzima denominada acetilcolinesterase. Essa enzima atua na degradação da acetilcolina, um neurotransmissor responsável pela transmissão dos impulsos no sistema nervoso (central e periférico). Uma vez inibida, essa enzima não consegue degradar a acetilcolina, ocasionando um distúrbio chamado de "crise colinérgica", principal responsável pelos sintomas observados nos eventos de intoxicação aguda por esses produtos.

Vários distúrbios do sistema nervoso foram associados à exposição aos agrotóxicos organofosforados, principalmente aqueles ligados à neurotoxicidade destes produtos, observados através de efeitos neurológicos retardados. Em

Tabela 1

Principais efeitos agudos e crônicos causados pela exposição aos agrotóxicos, de acordo com a praga que controlam e o grupo químico a que pertencem.

\begin{tabular}{|c|c|c|c|}
\hline $\begin{array}{l}\text { Classificação quanto à } \\
\text { praga que controlam }\end{array}$ & $\begin{array}{c}\text { Classificação quanto ao } \\
\text { grupo químico }\end{array}$ & $\begin{array}{c}\text { Sintomas de } \\
\text { intoxicação aguda }\end{array}$ & $\begin{array}{l}\text { Sintomas de } \\
\text { intoxicação crônica }\end{array}$ \\
\hline \multirow[t]{13}{*}{ Inseticidas } & Organofosforados/Carbamatos & Fraqueza & Efeitos neurotóxicos retardados \\
\hline & & Cólicas abdominais & Alterações cromossomiais \\
\hline & & Vômitos & Dermatites de contato \\
\hline & & Espasmos musculares & \\
\hline & & Convulsões & \\
\hline & Organoclorados & Náuseas & Lesões hepáticas \\
\hline & & Vômitos & Arritmias cardíacas \\
\hline & & Contrações musculares & Lesões renais \\
\hline & & involuntárias & Neuropatias periféricas \\
\hline & Piretróides sintéticos & Irritações das conjuntivas & Alergias \\
\hline & & Espirros & Asma brônquica \\
\hline & & Excitação & Irritações nas mucosas \\
\hline & & Convulsões & Hipersensibilidade \\
\hline \multirow[t]{5}{*}{ Fungicidas } & Ditiocarbamatos & Tonteiras & Alergias respiratórias \\
\hline & & Vômitos & Dermatites \\
\hline & & Tremores musculares & Mal de Parkinson \\
\hline & & Dor de cabeça & Cânceres \\
\hline & Fentalamidas & - & Teratogêneses \\
\hline \multirow[t]{11}{*}{ Herbicidas } & Dinitrofenóis/Pentaclorofenol & Dificuldade respiratória & Cânceres (PCP - \\
\hline & & Hipertermia & formação de dioxinas) \\
\hline & & Convulsões & Cloroacnes \\
\hline & Fenoxiacéticos & Perda do apetite & Indução da produção \\
\hline & & Enjôo & de enzimas hepáticas \\
\hline & & Vômitos & Cânceres \\
\hline & & Fasciculação muscular & Teratogênese \\
\hline & Dipiridilos & Sangramento nasal & Lesões hepáticas \\
\hline & & Fraqueza & Dermatites de contato \\
\hline & & Desmaios & Fibrose pulmonar \\
\hline & & Conjuntivites & \\
\hline
\end{tabular}

Fonte: Peres \& Moreira 48. 
um estudo anteriormente realizado em uma comunidade agrícola do Município de Nova Friburgo 20 , observamos que $30 \%$ dos trabalhadores desta comunidade apresentavam um quadro de polineuropatia periférica e alterações comportamentais que remetem a distúrbios do sistema nervoso central. A análise estatística demonstrou que a média de atividade de acetilcolinesterase do grupo que apresentava fasciculação foi significativamente inferior (decorrente de sua inibição) em relação ao grupo que não apresentava este sinal, demonstrando a relação direta entre a exposição a este grupo de agentes agrotóxicos e o desenvolvimento de doenças do sistema nervoso central. Esse mesmo estudo mostrou que 20\% das crianças da localidade apresentavam atividade colinesterásica diminuída, indicando sua exposição a agrotóxicos. Muitas dessas crianças diziam não trabalhar diretamente na lavoura, se referindo apenas a uma "ajuda" aos pais e, nesta condição, muitas vezes, estavam mais expostas por se protegerem inadequadamente, já que na sua percepção não iriam sofrer uma exposição direta.

Os inseticidas da classe dos organoclorados são agentes químicos que têm a capacidade de se acumular nas células gordurosas do organismo humano e de outros animais, o que pode vir a determinar uma série de efeitos indesejados à saúde. Além disso, os organoclorados são muito estáveis e podem persistir nos organismos e no ambiente por mais de trinta anos. Apesar de proibidos há mais de vinte anos, alguns agentes organoclorados, como o DDT, ainda são utilizados na agricultura, inclusive na região serrana do Estado do Rio de Janeiro, frutos de contrabando e comércio ilegal. Desde a década de 90, diversos estudos vêm apontando a possível relação entre a exposição ambiental e ocupacional a agrotóxicos organoclorados e o desenvolvimento de alguns tipos de câncer, como os cânceres de mama, pulmão, estômago, pâncreas e próstata $35,36,37,38,39$. Um estudo realizado por Meyer et al. 40, com dados de mortalidade por câncer na região serrana do Rio de Janeiro, mostrou uma elevada incidência de mortes por cânceres de estômago, esôfago e laringe entre homens agricultores no período de 1979 a 1998, comparado a outras populações masculinas da mesma faixa etária 40 . Esses autores discutem a relação entre a exposição ocupacional a organoclorados, entre outras classes de agrotóxicos, com a incidência de casos tão significativa.

Em outro estudo, esse mesmo grupo de pesquisadores já havia indicado uma possível associação entre a exposição a agrotóxicos organoclorados e distúrbios reprodutivos 41. Agrotóxicos de vários tipos têm sido correlacionados com efeitos reprodutivos em animais e seres humanos. O mancozeb e o amitrol possuem atividade inibidora da tireóide e os herbicidas triazínicos estão associados ao aparecimento de alguns tipos de cânceres hormônio-dependentes 42 . Todos utilizados na região serrana do Estado do Rio de Janeiro.

\section{Agrotóxicos e o ambiente}

A larga utilização de agrotóxicos no processo de produção agropecuária, entre outras aplicações, tem trazido uma série de transtornos e modificações para o ambiente, seja através da contaminação das comunidades de seres vivos que o compõem, seja através da sua acumulação nos segmentos bióticos e abióticos dos ecossistemas (biota, água, ar, solo, sedimentos etc.). Um dos efeitos ambientais indesejáveis dos agrotóxicos é a contaminação de espécies que não interferem no processo de produção que se tenta controlar (espécies não-alvos), dentre as quais se inclui, conforme discutido no item anterior, a espécie humana. A Tabela 2 apresenta o grau de toxicidade (variando em uma escala de 1 a 5) e a persistência (variando também em uma escala de 1 a 5) para os principais grupos de animais atingidos pela contaminação ambiental por agrotóxicos, exceto a espécie humana.

Em estudo realizado em localidade rural do Município de Nova Friburgo 20, observamos que a dispersão de agrotóxicos no ambiente, em particular nos recursos hídricos, ocasionava impacto significativo na ocorrência e distribuição de espécies animais. Nesse estudo, os organismos associados ao compartimento coluna d'água se mostravam afetados mais diretamente (táxons de hábitos natatórios e aqueles que vivem fixados a pedras). Em geral, tais organismos são coletores ativos, passivos ou raspadores-herbívoros, alimentando-se principalmente de material orgânico em suspensão ou de detritos e perifíton. Observou-se que, nessa região, os indivíduos das ordens Ephemeroptera e Plecoptera foram os mais afetados, pois, além de apresentarem tais hábitos, são organismos reconhecidamente sensíveis ${ }^{43}$. Tal fato é de extrema importância não apenas porque nós, humanos, somos os consumidores de alguns desses animais - peixes e crustáceos em particular - mas também pelo impacto indireto deste tipo de contaminação. É o caso do impacto sobre comunidades de insetos controladores de vetores de doença: se estes insetos controladores - predadores naturais de vetores de doenças - são atingidos pela dispersão ambiental de agrotóxicos, podem ter suas populações diminuídas e, assim, favorecer o aumento 
Toxicidade e persistência ambiental de alguns agrotóxicos (escala de 1 a 5).

\begin{tabular}{|c|c|c|c|c|c|}
\hline \multirow[t]{2}{*}{ Agrotóxicos } & \multicolumn{4}{|c|}{ Toxicidade } & \multirow{2}{*}{$\begin{array}{l}\text { Persistência } \\
\text { no ambiente }\end{array}$} \\
\hline & Mamíferos & Peixes & Aves & Insetos & \\
\hline Permetrina & 2 & 4 & 2 & 5 & 2 \\
\hline DDT & 3 & 4 & 2 & 2 & 5 \\
\hline Lindano & 3 & 3 & 2 & 4 & 4 \\
\hline Etil-paration & 5 & 2 & 5 & 5 & 2 \\
\hline Malation & 2 & 2 & 1 & 4 & 1 \\
\hline Carbaril & 2 & 1 & 1 & 4 & 1 \\
\hline Metoprene & 1 & 1 & 1 & 2 & 2 \\
\hline Bacillus thuringiensis & 1 & 1 & 1 & 1 & 1 \\
\hline
\end{tabular}

Fonte: Peres \& Moreira 48.

da circulação destes vetores em áreas habitadas por comunidades de seres humanos.

Outro importante impacto ambiental causado por agrotóxicos é a contaminação de coleções de águas superficiais e subterrâneas. De acordo com Zebarth ${ }^{44}$, a deterioração das águas subterrâneas e superficiais representa o impacto ambiental adverso mais importante associado à produção agrícola. Um estudo realizado em localidade agrícola de Nova Friburgo, 45 detectou concentrações de agrotóxicos anticolinesterásicos em valores até oito vezes acima do limite permitido pela legislação brasileira 46 em dois pontos de um importante curso hídrico regional, pontos estes localizados em áreas onde a atividade agrícola era mais intensiva, com as lavouras chegando até às margens do rio. Em outro estudo, realizado numa bacia hidrográfica do Município de Paty do Alferes 47 , observou-se que tanto o solo local quanto os sedimentos do leito do rio estavam contaminados por metais pesados oriundos da deposição de agrotóxicos e fertilizantes, o que pode gerar uma série de problemas ambientais e de saúde, pela acumulação e biomagnificação destes elementos ao longo da cadeia trófica.

Uma análise realizada em amostras de produtos da lavoura (900 amostras de 37 produtos diferentes) adquiridos no mercado distribuidor de Nova Friburgo, mostrou elevada porcentagem (33\% em tomate, $40 \%$ da vagem e $20 \%$ do pimentão) de contaminação por agentes anticolinesterásicos 20 , demonstrando a existência de resíduos indesejáveis nos produtos analisados, consumidos pela população local e da região metropolitana do Rio de Janeiro, entre outros estados.

Destacamos aqui, ainda, a reutilização, o descarte e/ou destinação inadequada das embalagens vazias de agrotóxicos, que favorecem a contaminação ambiental e provocam efeitos adversos á saúde humana, de animais silvestres e domésticos. Apesar da obrigatoriedade dos usuários devolverem essas embalagens aos estabelecimentos comerciais e da responsabilidade das empresas produtoras e comerciantes pelo recolhimento e destinação adequada das suas embalagens vazias, prevista desde de 6 de junho de 2000, quando da publicação da Lei no. 9.974, alterando a Lei no. 7.802/89, tal fato não se constitui, ainda, prática adotada pela maioria dos agricultores da região. Anualmente, os agrotóxicos comercializados no país, estão sendo colocados no mercado por meio de cerca de 130 milhões de unidades de embalagens e são recolhidas e destinadas adequadamente, somente, $10 \%$ a $20 \% 48$. Estudos realizados na região serrana do Rio de Janeiro, como os de Peres et al. 49,50 e Delgado \& Paumgartten ${ }^{31}$, fornecem indícios que essa situação se repete na região, apesar da existência de centros de coleta de embalagens próximos às zonas rurais.

\section{Percepção e comunicação de riscos}

A contaminação humana e ambiental por agrotóxicos está longe de ser um problema simples, muito em parte pela diversidade de determinantes (de ordens social, econômica e cultural) que o permeiam. O modelo clássico da avaliação de riscos, que inclui etapas como a identificação do perigo, caracterização do risco, avaliação doseresposta, comunicação e gerenciamento de riscos (que no campo se traduz primordialmente na identificação de fontes, quantificação da "carga" de agentes a que as populações estão expostas e a determinação da exposição/contaminação des- 
tas populações, através de diversos indicadores, conforme anteriormente discutido) apresentase incompleto para uma análise mais aprofundada deste problema. A este, deve-se somar as análises dos determinantes sociais e econômicos relacionados com a opção (ou imposição) do uso de agrotóxicos no processo de produção agrícola e a avaliação das formas através das quais as populações humanas interpretam os perigos representados pelo uso intensivo destes agentes químicos. Para esses casos, os estudos de percepção de riscos têm uma importante contribuição a dar, e devem estar intrinsecamente posicionados nas estratégias de avaliação e gerenciamento de riscos relacionados ao uso de agrotóxicos na lavoura 49,50.

Estudos anteriores sobre a percepção de risco de trabalhadores rurais sobre o uso de agrotóxicos em áreas agrícolas da região serrana do Estado do Rio de Janeiro 49,50 indicam que as mulheres destacam-se, enquanto um grupo específico, pela diferenciação de suas percepções de riscos relacionados à exposição aos agrotóxicos. Por desconsiderarem (ou submensurarem) os riscos relacionados ao processo de auxílio à pulverização química (a "puxada de mangueira"), acabam por se expor mais aos efeitos nocivos dos agrotóxicos, o que, juntamente com o fato de ficarem responsáveis pela lavagem das roupas e equipamentos utilizados na pulverização, faz com que esse grupo possa ser considerado como altamente vulnerável, necessitando de um cuidadoso e específico olhar 49.

Os homens também representam um grupo vulnerável, tanto em função de conduzirem, quase que exclusivamente, o processo de pulverização, quanto pelo fato de mascararem os riscos a este processo relacionados, através de estratégias defensivas. Dessa forma, acabam por se expor, muitas vezes, deliberadamente, aos efeitos nocivos desses agentes químicos, como forma de legitimar um ato de bravura, "machesa" e confiança junto a outros indivíduos desse grupo, amplificando o risco de sua exposição e das conseqüências adversas 50 .

A grande maioria dos estudos sobre a contaminação humana e ambiental por agrotóxicos não leva em consideração a dimensão social deste problema, focalizando suas investigações nas análises técnicas do risco, baseadas nos conhecimentos da toxicologia e das ciências atuariais 50. A partir desse ponto de vista, grupos populacionais específicos expostos a agrotóxicos são avaliados por parâmetros equânimes (indicadores de efeito, dados sobre a contaminação ambiental, identificação das vias de intoxicação etc.) 48. A grande questão é que as pessoas tendem a responder de maneiras diferentes frente aos perigos a que estão expostas. Um engenheiro de segurança de um planta industrial tem uma interpretação dos perigos oriundos do seu funcionamento diferente daquela da população residente nas áreas circunvizinhas; um agrônomo pode dimensionar um determinado risco de maneira oposta a um trabalhador rural. Ao deparar-se frente a um determinado perigo, advindo do processo de trabalho, um agricultor responde de acordo com as suas crenças, experiências, imagens e informações construídas ao longo de sua trajetória de vida. A percepção do risco é fruto da associação de todos esses determinantes com o cenário em que se encontra, no momento. Assim, não há como conceber uma avaliação de riscos desconexa com as crenças, interpretações e reações dos sujeitos envolvidos.

Como observado em um estudo anterior 51, a formação cada vez mais especializada dos profissionais e seu despreparo para o convívio com grupos sociais distintos acabam determinando sua insegurança na confrontação de uma realidade nova - ou com interlocutor desconhecido. Assim, tendem a aferrar-se aos seus próprios conhecimentos, reproduzindo assim sua própria visão de mundo e a impondo como modelo àqueles grupos 51 . Como decorrência, cada vez mais observamos o distanciamento entre os saberes técnicos e o senso comum, fato este que, no meio rural, é mais evidenciado nas estratégias de comunicação de risco.

A maioria das informações disponíveis sobre essas substâncias é ininteligível pelos trabalhadores rurais, o que aumenta o risco associado ao seu uso. A análise dos dados de um estudo de recepção das informações sobre agrotóxicos na região serrana do Estado do Rio de Janeiro 51 apontou para uma não compreensão de tais informações. Em alguns casos, observou-se que a interpretação do agricultor era oposta ao sentido da mensagem (inversão da mensagem), o que não apenas caracteriza o fracasso da comunicação como pode levar o trabalhador à adoção de práticas perigosas.

As informações sobre agrotóxicos disponíveis ao homem do campo são, ainda, inteiramente dependentes de uma série de interesses (econômicos, principalmente) que criam "necessidades", visando a legitimar o uso destes agentes químicos. $\mathrm{O}$ discurso ora vigente no campo (e presente em cartilhas, cartazes, folders e toda a sorte de material disponível para o trabalhador rural) enfatiza a necessidade do uso de agrotóxicos como único meio de se acabar com a fome do mundo. Vejamos alguns exemplos que apontam para a origem desse discurso: "A demanda de crescimento da população mundial por alimentos e fibras requer uma agricultura que produza 
grande quantidade por área cultivada. Alimentar as populações futuras da mesma forma como é realizado hoje em dia não é viável: isto requereria um drástico aumento da área cultivada e a redução de florestas naturais. Em muitas partes do mundo não há mais terras aráveis disponíveis. Em outras, uma expansão da área plantada seria ambientalmente e socialmente inaceitável. O aumento da produção a partir da atual área plantada requer o uso de boas práticas agrícolas para combater as perdas causadas nas colheitas. O desafio está em conseguir isto sem afetar o meio ambiente e os recursos naturais para as gerações futuras de consumidores e agricultores. O uso de produtos fitossanitários e da biotecnologia é um importante princípio sobre os quais a proteção de plantas sustentável pode ser baseada" (Andef, 1999, apud Peres \& Moreira 48; p. 333).

"Nossa responsabilidade para com as gerações futuras significa que nós devemos praticar uma agricultura sustentável, garantir que as lavouras serão protegidas e explorar as terras disponíveis à agricultura de modo intensivo. Este é o único meio de garantir que as necessidades de alimento da população, a qual ainda está em crescimento, continuem existentes no próximo milênio - de acordo com as estimativas atuais, a qual está abaixo de 6 bilhões de pessoas, haverá um crescimento de 80 milhões de pessoas ao ano, até o ano de 2020, levando a população mundial para mais de 8 bilhões. Uma agricultura de forma sustentável, propriamente praticada, a qual atinja produtividade máxima, porém com mínimos efeitos adversos para o nosso ambiente, é essencial para prover alimento suficiente para atender às demandas mundiais" (Bayer, 1999, apud Peres \& Moreira 48; p. 333).

Como resultado, todos os trabalhadores ouvidos durante os estudos aqui sumarizados relataram não haver alternativa viável ao uso de agrotóxico. Tal fato - impreciso e inverídico - acaba por legitimar a aceitação de práticas perigosas de controle de pragas, por meio do uso de agrotóxicos, expondo um enorme contingente de trabalhadores rurais brasileiros a uma gama de riscos à sua saúde, muitos dos quais desconhecidos, até o momento.

\section{Considerações finais}

O problema de alimentação está longe de ser resolvido pelo simples aumento da produti- vidade agrícola, mesmo porque o modelo de produção hoje adotado é capaz de suprir, com sobras, a demanda ora existente. Ademais, outras técnicas de controle de pragas alternativas aos agrotóxicos são, hoje, uma realidade, tanto em termos da produtividade quanto em relação aos custos, além de apresentarem um potencial de contaminação humana ou ambiental muito menor ou mesmo desprezível. O controle dos problemas relacionados ao uso indiscriminado de agrotóxicos, já identificados e bem conhecidos, somente poderá ser alcançado com a adoção de práticas alternativas ou, quando estritamente necessário, pelo uso seguro e cuidadoso destas substâncias. Para tal, governo e sociedade organizada devem estar unidos dentro de um objetivo maior que o lucro: a garantia da qualidade de vida do trabalhador rural e da população, consumidora dos produtos provenientes da lavoura, assim como a garantia da sustentabilidade do ambiente.

A análise dos resultados de estudos desenvolvidos por nosso grupo de pesquisa há nove anos na região serrana do Estado do Rio de Janeiro, permite identificar alguns dos determinantes da situação do trabalho rural face ao uso de agrotóxicos. Primeiro, a carência educacional e de formação dos agricultores da região - realidade esta nada diferente de outras regiões do país - contribui para a dificuldade da correta interpretação de informações sobre saúde e segurança no manuseio de agentes químicos perigosos, como os agrotóxicos ${ }^{48}$. Segundo, a maioria da informação disponível ao agricultor sobre os agrotóxicos provém da própria indústria química 51, e é disseminada por técnicos ligados ao comércio de insumos agrícolas, o que compromete sua isenção e qualidade. Terceiro, a carência de políticas governamentais voltadas ao acompanhamento e fiscalização das atividades do homem do campo afastam, ainda mais, estes indivíduos dos saberes disponíveis sobre as práticas de proteção de lavouras e combate às pragas. Soma-se a esses fatores a forte influência das políticas de incentivo à produção agrícola, quase todas fortemente associadas ao aumento do consumo de agentes químicos, em particular agrotóxicos.

A superação desse desafio é mais que um problema de saúde: é um nítido exemplo da necessidade de se integrar os setores saúde e ambiente em torno da garantia da qualidade de vida das populações do campo e da cidade, tendo como conceito norteador a sustentabilidade ambiental. 


\section{Resumo}

O uso de agrotóxicos na lavoura é uma realidade nacional, assim como é do tamanho de nosso país a dimensão dos problemas relacionados a este uso. Sua ampla e crescente utilização no processo de produção agropecuária, entre outras aplicações, tem gerado uma série de transtornos e modificações para o ambiente, seja através da contaminação das comunidades de seres vivos que o compõem, seja através da sua acumulação nos segmentos bióticos e abióticos dos ecossistemas (biota, água, ar, solo, sedimentos etc.). Também se apresenta como determinante de uma série de doenças e agravos à saúde das populações humanas. $O$ presente trabalho discute algumas implicações do uso de agrotóxicos para a saúde humana e o ambiente da região serrana do Estado do Rio de Janeiro, importante pólo agrícola estadual. Para tanto, apresenta resultados de estudos realizados na região, apontando para os possiveis determinantes do quadro ora vigente na região e alguns dos principais desafios de superação do problema.

Uso de Praguicidas; Trabalhadores Rurais; Poluição Ambiental

\section{Colaboradores}

F. Peres e J. C. Moreira participaram de todas as etapas de desenvolvimento do presente manuscrito, incluindo o trabalho de campo, a revisão bibliográfica e a redação do texto.

\section{Referências}

1. Food and Agriculture Organization of the United Nations. Faostat: agricultural database. http:// apps.fao.org / faostat/collections?version=ext\&h asbulk=0\&subset=agriculture (acessado em 12/ Jan/2005).

2. Agência Nacional de Vigilância Sanitária. Nota técnica sobre livre comércio de agrotóxicos e impactos à saúde humana. http://www.pronaf.gov. br/dater/arquivos/livre_comercio_agrotoxicos. pdf (acessado em 18/Jan/2007).

3. Ministério do Meio-Ambiente. Informativo MMA 2000; 15. http://www.mma.gov.br/port/ascom/ imprensa/marco2000/informma15.html (acessado em 20/Ago/2001).

4. Yudelman M, Ratta A, Nygaard D. Pest management and food production looking to the future. Washington DC: International Food Policy Research Institute; 1998. (Food, Agriculture and Environment Discussion Paper, 25).
5. Ministério da Agricultura, Pecuária e Abastecimento. Plano agrícola e pecuário 2004/2005 - íntegra do discurso do Ministro da Agricultura, Pecuária e Abastecimento, Roberto Rodrigues, no Palácio do Planalto. http://www.agricultura.gov.br/pls/ portal/docs/PAGE/MAPA/PLANOS/PAP_2004_ 2005/DEGRAVA\%C7AO\%20PLANO\%20SAFRA\%20 RR\%201806.pdf (acessado em 15/Jan/2005).

6. Fernandez-Cornejo J, McBride W. Genetically engineered crops for pest management in the US. Washington DC: US Department of Agriculture; 2000. (Agricultural Economics Report, 786).

7. Dias GLS, Amaral CM. Mudanças estruturais na agricultura brasileira: 1980-1998. Santiago de Chile: Comisión Económica para la América Latina y el Caribe/Naciones Unidas; 2001. (Serie Desarrollo Productivo, 99). 
8. Brandão ASP, Rezende GC, Marques RWC. Crescimento agrícola no período 1999-2004: explosão da área plantada com soja e meio ambiente no Brasil. Rio de Janeiro: Instituto de Pesquisa Econômica Aplicada; 2005. (Texto para Discussão, 1062).

9. Miranda AC, Moreira JC, Carvalho RL, Peres F. Neoliberalism, pesticide use and the food sovereignty in Brazil. In: Breilh J, editor. Latin America health watch (Alternative Latin American Health Report). Quito: Centro de Estudios y Asesoría en Salud; 2005. p. 115-23.

10. Vilela NJ, Lopes FJ, Fontes RR. Aspectos socioeconômicos das hortaliças no Brasil. http://www. agricultura.gov.br/pls/portal/docs/PAGE/MAPA/ CAMARAS CONSELHOS/CAMARA HORTALICAS/ REUNIOES_CAMARA_HORTALICAS/ASP_ SOCIOECO.pdf (acessado em 30/Abr/2006).

11. Almeida WF, Garcia EG. Exposição dos trabalhadores rurais aos agrotóxicos no Brasil. Rev Bras Saúde Ocup 1991; 19:7-11.

12. Gonzaga MC, Santos SO. Avaliação das condições de trabalho inerentes ao uso de agrotóxicos nos Municípios de Fátima do Sul, Glória de Dourados e Vicentina - Mato Grosso do Sul - 1990. Rev Bras Saúde Ocup 1992; 20:42-6.

13. Faria NMX, Facchini LA, Fassa AG, Tomasi E. Estudo transversal sobre saúde mental de agricultores da Serra Gaúcha (Brasil). Rev Saúde Pública 1999; 33:391-400.

14. Faria NMX, Facchini LA, Fassa AG, Tomasi E. Processo de produção rural e saúde na serra gaúcha: um estudo descritivo. Cad Saúde Pública 2000; 16:115-28.

15. Vaughan E. Chronic exposure to an environmental hazard: risk perceptions and self-protective behavior. Health Psychol 1993; 12:74-85.

16. McDuffie HH. Women at work: agriculture and pesticides. J Occup Med 1994; 36:1240-6.

17. Hunt L, Tinoco R, Halperin D, Schwartz N. Balancing risks and resources: applying pesticides without protective equipment in Southern Mexico. In: Hahn R, editor. Anthropology in public health: bridging differences in culture and society. Oxford: Oxford University Press; 1999. p. 122-48.

18. Arcury TA, Quandt SA, Dearry A. Farmworker pesticide exposure and community-based participatory research: rationale and practical applications. Environ Health Perspect 2001; 109 Suppl 3:429-34.

19. McCauley LA, Lasarev MR, Higgins G, Rothlein J, Muniz J, Ebbert C, et al. Work characteristics and pesticide exposures among migrant agricultural families: a community-based research approach. Environ Health Perspect 2001; 109:533-8.

20. Moreira JC, Jacob SC, Peres F, Lima JS, Meyer A, Oliveira-Silva JJ, et al. Avaliação integrada do impacto do uso de agrotóxicos sobre a saúde humana em uma comunidade agrícola de Nova Friburgo/RJ. Ciênc Saúde Coletiva 2002; 7:299-311.

21. Empresa Estadual de Pesquisa Agropecuária do Rio de Janeiro. Informativo PESAGRO-Rio. http:// www.pesagro.rj.gov.br/pesquisas/ambiente.htm (acessado em 30/Abr/2006).

22. Theodoro GF, Maringoni AC. In vitro and in vivo action of chemicals on Clavibacter michiganensis subsp. michiganensis, causal agent of the bacterial canker of tomato. Scientia Agrícola 2000; 57:439-43.
23. Lopes MC, Stripari PC. A cultura do tomateiro. In: Gotp R, Tivelli SW, organizadores. Produção de hortaliças em ambiente protegido. São Paulo: Editora Unesp; 1998. p. 257-304.

24. Machado Neto JG. Quantificação e controle da exposição dérmica de aplicadores de agrotóxicos em culturas estaqueadas de tomate, na região de Cravinhos-SP [Tese de Doutorado]. Jaboticabal: Faculdade de Ciências Agrárias e Veterinária, Universidade Estadual de São Paulo; 1990.

25. Azaroff L. Biomarkers of exposure to organophosphorous insecticides among farmers' families in rural El Salvador: factors associated with exposure. Environ Res 1999; 80:138-47.

26. Araújo ACP, Nogueira DP, Augusto LGS. Impacto dos praguicidas na saúde: estudo da cultura de tomate. Rev Saúde Pública 2000; 34:309-13.

27. Soares W, Almeida RMVR, Moro S. Trabalho rural e fatores de risco associados ao regime de uso de agrotóxicos em Minas Gerais, Brasil. Cad Saúde Pública 2003; 19:1117-27.

28. Soares W, Almeida RMVR, Moro S. Rural worker's health and productivity: an economic assessment of pesticide use in Minas Gerais, Brazil. Appl Health Econ Health Policy 2002; 1:157-64.

29. Coutinho JAG, Freitas EAV, Cavalcanti MAS, Ferry RV, Lins LGC, Santos JA, et al. Uso de agrotóxicos no Município de Paty do Alferes: um estudo de caso. Cadernos de Geociências 1994; 10:23-31.

30. Oliveira-Silva JJ, Alves SR, Meyer A, Peres F, Sarcinelli PN, Mattos RCO, et al. Influência de fatores socioeconômicos na contaminação por agrotóxicos, Brasil. Rev Saúde Pública 2001; 35:130-5.

31. Delgado IF, Paumgartten FJR. Pesticide use and poisoning among farmers from the county of Paty do Alferes, Rio de Janeiro, Brazil. Cad Saúde Pública 2004; 20:180-6.

32. Soares WV, Freitas EAV, Coutinho JAG. Trabalho rural e saúde: intoxicações por agrotóxicos no Município de Teresópolis-RJ. Revista de Economia e Sociologia Rural 2005; 43:685-701.

33. Chester MH, Adam AV, Inkmann-Koch A, Litchfiel MH, Sabapathy R, Tuiman CP. Field evaluation of protective equipment for pesticide appliers in a tropical climate. In: Forget G, Goodman T, Villiers A, editors. Proceedings of the I Symposium Impact of Pesticide use on Health in Developing Countries. Ottawa: International Development Research Centre; 1993. p. 116-23.

34. Sistema Nacional de Informações Tóxico-farmacológicas. Casos registrados de intoxicação humana e envenenamento. Brasil, 2003. http://www. fiocruz.br/sinitox/2003/umanalise2003.htm (acessado em 30/Abr/2006).

35. Moysich KB, Ambrosone CB, Vena JE, Shields PG, Mendola P, Kostyniak P, et al. Environmental organochlorine exposure and postmenopausal breast cancer risk. Cancer Epidemiol Biomarkers Prev 1998; 7:181-8.

36. Dorgan JF, Brock JW, Rothman N, Needham LL, Miller R, Stephenson HE, et al. Serum organochlorine pesticides and PCBs and breast cancer risk: results from a prospective analysis (USA). Cancer Causes Control 1999; 10:1-11. 
37. Baris D, Kwak LW, Rothman N, Wilson W, Manns A, Tarone RE, et al. Blood levels of organochlorines before and after chemotherapy among non-Hodgkin's lymphoma patients. Cancer Epidemiol Biomarkers Prev 2000; 9:193-7.

38. Hoppin JA, Tolbert PE, Holly EA, Brock JW, Korrick SA, Altshul LM, et al. Pancreatic cancer and serum organochlorine levels. Cancer Epidemiol Biomarker Prev 2000; 9:199-205.

39. Parent ME, Siemiatycki J. Occupation and prostate cancer. Epidemiol Rev 2001; 23:138-43.

40. Meyer A, Chrisman J, Moreira JC, Koifman S. Cancer mortality among agricultural workers from Serrana Region, state of Rio de Janeiro, Brazil. Environ Res 2003; 93:264-71.

41. Koifman S, Koifman RJ, Meyer A. Human reproductive system disturbances and pesticide exposure in Brazil. Cad Saúde Pública 2002; 18:435-45.

42. Cocco P. On the rumors about the silent spring. Review of the scientific evidence linking occupational and environmental pesticide exposure to endocrine disruption health effects. Cad Saúde Pública 2002; 18:379-402.

43. Silveira MP, Baptista DF, Buss DF, Nessimian JL, Egler M. Application of biological measures for stream integrity assessment in south-east Brazil. Environ Monit Assess 2005; 101:117-28.

44. Zebarth BJ. Improved manure, fertilizer and pesticide management for reduced surface and groundwater. Ottawa: The Pacific Agri-Food Research Centre; 1999. (The Pacific Agri-Food Research Centre Technical Publications, 23).
45. Alves SR, Oliveira-Silva JJ. Avaliação de ambientes contaminados por agrotóxicos. In: Peres F, Moreira JC, organizadores. É veneno ou é remédio? Agrotóxicos, saúde e ambiente. Rio de Janeiro: Editora Fiocruz; 2003. p. 137-56.

46. Comissão Nacional do Meio Ambiente. Resolução Conama $n^{\circ}$. 20, de 18 de junho de 1986. Brasília: Comissão Nacional do Meio Ambiente; 1986.

47. Ramalho FGP, Amaral-Sobrinho NMB, Velloso ACX. Contaminação da microbacia de Caetés com metais pesados pelo uso de agroquímicos. Pesquisa Agropecuária Brasileira 2000; 35:1289-303.

48. Peres F, Moreira JC, organizadores. É veneno ou é remédio? Agrotóxicos, saúde e ambiente. Rio de Janeiro: Editora Fiocruz; 2003.

49. Peres F, Lucca SR, Ponte LMD, Rodrigues KM, Rozemberg B. Percepção das condições de trabalho em uma tradicional comunidade agrícola em Boa Esperança, Nova Friburgo, Rio de Janeiro, Brasil. Cad Saúde Pública 2004; 20:1059-68.

50. Peres F, Rozemberg B, Lucca SR. Percepção de riscos no trabalho rural em uma região agrícola do Estado do Rio de Janeiro, Brasil: agrotóxicos, saúde e ambiente. Cad Saúde Pública 2005; 21:1836-44.

51. Peres F, Rozemberg B, Alves SR, Moreira JC, Oliveira-Silva JJ. Comunicação relacionada ao uso de agrotóxicos em uma região agrícola do Estado do Rio de Janeiro. Rev Saúde Pública 2001; 35:56470 .

Recebido em 04/Mai/2006

Versão final reapresentada em 09/Nov/2006 Aprovado em 15/Jan/2007 